\title{
Developing a Robust Teaching Portfolio as a Doctoral Student in a Research- Intensive Engineering Program
}

\section{Dr. Anahid Behrouzi, California Polytechnic State University - San Luis Obispo}

Anahid Behrouzi is a new assistant professor at Cal Poly - San Luis Obispo and recently completed her doctoral degree in civil engineering at the University of Illinois at Urbana-Champaign. She has been involved with STEM education beginning in 2003 as a volunteer and summer instructor with the North Carolina Museum of Life and Science. She has been engaged with undergraduate/ graduate course delivery in the topic areas of engineering problem-solving and structural engineering at North Carolina State University (2008-2011), the University of Illinois at Urbana-Champaign (2012-2015),Tufts University (2015-2016), and Cal Poly - San Luis Obispo (2016-Present). She has a BS in civil engineering and BA in Spanish language \& literature from North Carolina State University, and a MS/PhD in civil engineering from the University of Illinois at Urbana-Champaign. 


\title{
DEVELOPING A ROBUST TEACHING PORTFOLIO AS A DOCTORAL STUDENT IN A RESEARCH-INTENSIVE ENGINEERING PROGRAM
}

\begin{abstract}
Successful faculty applications to teaching/undergraduate institutions can be difficult for doctoral students transitioning directly from a research-intensive engineering program. Oftentimes, these prospective faculty members have limited opportunities to engage in engineering education research, to serve as a primary instructor for a lecture course, or to receive adequate mentoring to prepare them for the environment of a teaching/undergraduate institution.

This paper will highlight the lessons learned by a new faculty member at a top-ranked undergraduate institution (and recent doctoral degree recipient at a R1 research institution) about how students can build a comprehensive teaching portfolio outside of the traditional coursework and research path required for an engineering doctoral degree. This paper includes a discussion of various approaches to leverage extracurricular, teaching-related activities that are available on a research campus.
\end{abstract}

\section{Importance of Teaching Portfolios}

Felder \& Brent (1996) define a teaching portfolio as a "collection of materials that document a professor's teaching goals, strengths, and accomplishments" which includes self-generated items (teaching philosophy and teaching materials); teaching products (graded assessments or publications related to education); and information generated by others (student/faculty evaluations). Other than serving in the summative evaluation of a prospective faculty member in the hiring process, the act of preparing for and developing such a portfolio has shown to improve teaching (Seldin 1993).

Reis (1997) underscores the importance of a portfolio that demonstrates concrete evidence of teaching experience not simply the potential for excellence in teaching. Reis further indicates that contrary to popular belief amongst prospective faculty, most departments hire primarily to address a teaching need rather than to fill a research void. Therefore, it is critical that future faculty not underestimate the importance of seeking out and documenting teaching opportunities.

\section{Challenges Associated with Developing a Robust Teaching Portfolio}

In a November 2013 article in The Chronicle of Higher Education, Derek Bok - former president of Harvard University - highlights the limited preparation Ph.D. students have to be educators:

"The most glaring defect of [American] graduate programs, however, is how little they do to prepare their students to teach. Doctoral candidates have long had the chance to assist professors in large lecture courses by leading weekly discussions among small groups of undergraduates. Yet only a minority of those assistants report that they receive adequate supervision by the faculty member in charge of the course. In fact, professors often tell their graduate students not to spend much time on their teaching duties, lest it distract them from the all-important task of writing a thesis [emphasis added]."

The deficiency of teaching experience for novice faculty can be observed in discussions by other leading engineering educators (Brent \& Felder 2000; Gaff 2002). Furthermore, the final statement from the excerpt from Bok is often true at research-intensive engineering institutions. 
Perhaps even more critical than the delay to a student's doctoral thesis completion, as identified by Bok, many faculty advisors view student-time spent teaching as directly conflicting with progress on experimental testing, computational simulation, and technical publication agreements with research sponsors. This perception of conflict is not unwarranted: faculty are at the behest of governmental/private entities that can freeze further funding or request recompense for previously distributed grants if project deliverables are not timely. A graduate student, or team of students, is a significant driver in moving the research forward to meet these sponsor commitments.

If you are reading this paper as a graduate student at a R1-R3 Carnegie Classification Institution, you probably familiar with meeting research demands from an external sponsor. Yet, we selfselected into this kind of environment; we wanted to attend a school with expert research faculty, unparalleled facilities, and state-of-the-art projects. In the technical engineering sense, we strive to answer questions no one has broached before and that is a task that consumes nearly all of our and our advisor's energies. While we are submersed in research work, we must also actively prepare for our long-term trajectory.

This paper is intended to serve as a guide that focuses particularly on the steps that a doctoral student can take while in a research-intensive institution to build a robust teaching portfolio to prepare for a future academic role. The opportunities discussed in this document are based largely on personal anecdotes and are directed towards students that would not have the opportunity to take courses related to or invest significant doctoral research efforts in engineering pedagogy. Readers should take the suggestions as a buffet of possibilities and select those that are accessible at their current institution, that meet the time-constraints of their schedule, and that will provide the most value for the type of institution they plan to join as faculty.

\section{Capitalizing on the Teaching Assistant Role}

There are several major reasons that drive faculty to employ their graduate students as teaching assistants in their courses, even when it directly conflicts with research demands.

- The simplest reason being that they need to distribute the responsibilities of the class so they have time to meet higher-order obligations of research. The grant and journal paper writing, meetings to garner support from domestic and international partners, as well as travelling to present at trade and academic conferences. The tasks that we graduate students can support, but ultimately our advisors carry out on a regular basis.

- Then there is the financial motivation for having us teach, that they need to keep us on payroll in times when we are conducting research but associated funds are unavailable. To clarify, the monies to support teaching assistants are provided by the department and allocated based on class size; it is a steady source of income that our advisors can depend on to ensure our support through graduate studies.

- The last, and often least likely scenario, is that they need our research expertise to complement class instruction particularly with advanced undergraduate/ graduate courses involving experimentation or computer simulation.

When you consider these motivations, it is logical that our involvement as a teaching assistant is typically limited to the grading of homework/projects; few, if any, office hours each week; and substitute lecturing during faculty travel. With advanced coursework, there may be the additional 
teaching opportunities to train students in designing, instrumenting, and analyzing experiments, or the equivalent with computer software.

It is important to understand the motivations of your faculty advisor with respect to your role as a graduate teaching assistant (GTA), but you should NOT resign yourself to the status quo of essential but non-lecturing teaching tasks. The remainder of this section outlines suggestions to grow as an educator based on your experience with a particular class and/or level of relationship with the course instructor. Similarly, Reis (1997) also proposes a helpful stage-by-stage process for students/post-docs to engage in increasingly independent, creative, and challenging teaching experiences accompanied by close faculty mentorship (Chapter 6: Teaching Experiences Prior to Becoming a Professor).

\section{First Time Class/New Relationship with Course Instructor (Level 1):}

Learn the Course Material

If it is the first time you are a GTA for a course, learn all that you can by attending each of the class sessions and taking notes as if you are enrolled in the course. Interact with the students during class breaks and be willing to answer their questions. You may not always have the knowledge or time to respond in that instant during class, so record student questions to follow up via email or in office hours. Developing rapport is important, as is tracking areas where students tend to have difficulties in a particular course.

Request additional resources from the course instructor (or previous GTAs) outside of the assigned class textbook including technical papers on research/industry projects, code and guide documents, other textbooks, additional problem-sets and their solutions. Use this literature as a starting point to clear up any uncertainties you have with the course material, and as a secondary step, develop targeted questions to pose to the course instructor. Seasoned faculty has a depth of knowledge in a topic area that has been cultivated over many years. As graduate students, we have to begin building this foundation from available resources and the expertise of our faculty. Reis (1997) considers this "leveraging" process critical - where a new teaching assistant takes a course in preparation to later teach the subject and while a GTA actively collects copies of course notes, assignments, labs, assessments, and other materials from the current instructor.

Develop Rapport with Students

In office hours, you will encounter learners at different levels of understanding who respond to a diverse range of teaching approaches. Be open to the fact that the learning style that works best for you may not resonate with a student, and we will often have to be creative problem-solvers as educators. With office hours, responding to email questions, and in grading, utilize positive reinforcement to create an encouraging environment so that students are motivated to take risks and engage in inquiry and exploration. Many teaching centers offer (some require) workshops for graders and teaching assistants, see section Engaging with Programs that Focus on Teacher Development.

Entry-level Instruction: Teach What You Know

At Level 1, independent teaching is likely still a new experience. When substituting during faculty absences, it would be appropriate to request and use lecture notes from the primary course instructor. Even though you may have not created the notes, reviewing the theory and 
working through any example problems or demonstrations is important. As a relatively new learner of the course topics yourself, this will help you build confidence in your understanding of the material and identify the types of questions students may ask. When leading tutorials on topics/techniques related to your doctoral research, be reassured that you already have command of the material you are teaching and it is matter of setting up an exercise that you can model (and/or students can participate in) where you break down a complex procedure into simple, discrete steps.

\section{Repeat Class/Established Relationship with Course Instructor (Level 2):}

The suggestions with Level 1 are consistent with what most university teaching centers will recommend for new graduate student graders or teaching assistants. Level 2 introduces novel approaches that allow GTAs to support curriculum development and establish a deeper sense of ownership in the course.

\section{Address Concept Challenges via Curriculum Development}

Prior to the start of the semester, summarize and reflect on the main course topics that challenged students in the previous course offering (this is why developing rapport was important - students will be more vocal if they feel comfortable revealing their insecurities to you). Investigate why those concepts were problematic and techniques that were effective that you, the primary instructor, or the students themselves implemented to overcome these obstacles.

Task \#1: Consider how to formally implement the effective measures in the current course to be proactive rather than reactive about student learning.

There may be concepts that students never fully understood. Take this opportunity to ask other GTAs about their instruction/learning experiences with the topic and conduct a review of online literature, video, and demonstration resources from faculty at peer institutions teaching similar courses. Focus on potential solutions that have minimal impact to preparation/teaching time while also being a cost-conscious use of materials or technology.

Task \#2: Develop or adapt explanations, graphics, hands-on activities, physical models, or other teaching tools that target two to four of the most challenging topics in the course.

Task \#3: Prepare a proposal for your course instructor that identifies the existing learning obstacles, your recommended solutions, and how these recommendations can be executed in an efficient and inexpensive manner.

\section{Advancing Instruction: Expand Your Horizons}

Having progressed through Level 1, you are acclimated with the class material and had a few opportunities to teach topics that you are familiar with via your research or using notes provided by the course instructor. Your past teaching was at the bequest of faculty, now is the time to begin volunteering to teach. As an initial step it is worth discussing with the course instructor your interest in a future in academia, and the value that teaching has in your professional preparation. Consistent with Level 2, you should be clear that the teaching experience you are seeking is different from the past because you either intend to learn material that is new to you and/or to create original lesson plans. Consider two avenues to volunteer-teach: 
- Couple your teaching request with one of the ideas you developed during the exercise in the previous section "Address Concept Challenges". Perhaps you prepare a hands-on demonstration and associated discussion questions for students to answer in teams; this could be 15-20 minutes of an existing faculty lecture. Or, it might be extended where you have the full class period and can more fully develop a particular topic.

- Provide a supplementary exam review session where you help students identify the interrelatedness between course topics they have learned to the current point in the class. After establishing this overall roadmap, you can focus on areas where past homework and tests indicate that students tend to have uncertainties.

Request Feedback from Engineering/Educational Experts and Students

At Level 2, begin soliciting formal feedback on your teaching. Request that your faculty advisor or course instructor observe you, they are the material experts when it comes to engineering. However, you should additionally schedule an observation with an educational consultant from the university teaching center or the College of Engineering (often the college has a sub-group dedicated to excellence in education). The value of the educational evaluator is that they are versed in pedagogical approaches that span a wide array of disciplines. In the ideal scenario, arrange a pre-observation meeting to discuss with your reviewers what and how you plan to teach as well as a debriefing to hear what they saw as successes and areas needing improvement.

Additionally, there is significant value in collecting student feedback. There are several studies that indicate students can serve as effective critics to assess teaching approaches in science curriculum (Redmond \& Clark 1982; Herreid \& Kozak 1995). Herreid and Kozak conclude that students "can be extremely informative about the educational experience if they are asked pointed questions about particular class presentations" and "should be included in faculty development ... as critics and consultants whenever possible...”. Student opinion can be particularly helpful as they are being simultaneously exposed to different teaching styles via their engineering and general education classes. While universities require that faculty distribute surveys at the end of the semester, this is optional for teaching assistants. Forms are often not distributed for teaching assistants unless requested early in the semester; therefore, it is important to meet the time window to request the forms. Also, teaching assistants need not use feedback forms targeted to ABET assessment that engineering faculty disperse, most campus teaching centers have alternate forms (or banks of questions) that focus on instructor performance.

\section{Engaging with Programs that Focus on Teacher Development}

While there are research-intensive institutions with an engineering education department where students can take targeted coursework to supplement their technical studies (Purdue, Virginia Tech, Ohio State), a majority of R1-R3 universities do not have extensive curriculum in this area. However, there are several campus programs available to graduate students to learn about postsecondary pedagogy, in general and specifically related to engineering. 


\section{University Center for Teaching \& Learning}

Consider a hub-and-spokes analogy where the campus center for teaching and learning (CTL) is the hub of educational expertise where the spokes - all other departments - should converge. The individual departments house subject-specific technical knowledge; the CTL does the same for diverse pedagogical knowledge. The faculty and staff in this unit have a command of research and practice related to learning psychology as well as teaching techniques and tools that apply across the technical and humanities fields. A selection of relevant opportunities offered by campus CTL's that are worthwhile to investigate as a graduate student are discussed below.

Teaching Symposia, Workshops, \& Reading Circles

Prior to each semester, many campus CTL units host a part-to-full day "Graduate Academy \& Grading Symposium" (sample schedule can be accessed at http://cte.illinois.edu/programs/ tatrain/Jan14GradAcademyProgram.pdf). This event includes presentations and simulation activities coordinated by tenure-track faculty, CTL staff, and senior graduate students. The symposia is targeted towards new graders and teaching assistants to discuss approaches to fairly evaluating and providing beneficial feedback to students, in addition to recommendations on how to conduct office hours. At the symposia, there are often brief previews of other workshops that the CTL puts on during the year. Other than being an active participant in these training activities, it is important to get on the listserv for subsequent CTL workshops as well as develop friendships with students in/outside of your home department that you can coordinate with (and provide peer motivation to) when planning to attend the workshops.

Review the subsequent emails that come from the CTL, and make efforts to attend workshops that you feel will further your teaching skillset. To provide a few brief examples, topics can include: writing effective rubrics, integrating hands-on activities in lecture classes to promote discovery-based learning, use of humor in the classroom, accessibility for students with disabilities, implementing technology like clickers and polling software, and so forth. Depending upon your level of interest and participation with CTL workshops, it is often possible for senior graduate students to transition into CTL consultants that host workshops as part of a team or individually.

In addition to workshops, many campus CTL units host semester-long book clubs where a group of 4-5 graduate students meet a few times a month to discuss the selected reading. Typically these activities are led by a more senior graduate student CTL consultant or a staff member. Again this is a beneficial way to be exposed to what teaching experts consider the most effective pedagogical practices while developing peer relationships outside of your department with other students who are passionate about education.

Microteaching \& Classroom Observations

The idea of requesting feedback on teaching was introduced previously in Capitalizing on the Teaching Assistant Role. The current section provides details on the two approaches that CTL units generally offer to graduate students: microteaching and classroom teaching observations. 
Microteaching is a brief, simulated teaching scenario. Typically the CTL will arrange 60-90 sessions where graduate students have the opportunity to select a topic and present a 5-8 minute lesson to an audience of peers. Students may choose to utilize a combination of PowerPoint presentation, board notes, handouts, interactive team activities, discussions; essentially any approach they feel will make their topic most interesting and understandable to their audience. The CTL staff or consultant facilitates the experience by conducting the observation, videorecording each presentation, and leading a group reflection at the end of the session. Additionally there is a private 30-45 minute debriefing meeting after the microteaching experience which involves watching the video with a CTL representative and receiving oral and written feedback on the successes/pitfalls of the simulated lesson. At the debriefing CTL staff is able to point out specific workshops, books, articles, and other resources to overcome identified weaknesses.

Classroom observation is fundamentally different, because it will typically consist of a full 1-2 hour class lecture/lab session with instruction of actual students who are expected to utilize what they have learned to complete graded homework, projects, and exams. Where microteaching is extremely condensed with respect to time and low-risk as it does not impact the audience's academic development, teaching associated with a classroom observation is more extensive and has to fit within the overall curriculum arc of a course. It is necessary to plan these observations in advance to coordinate with the teaching plans of the primary course instructor and the schedule of a CTL representative that will conduct the observation (and pre-/post-observation meetings to provide feedback). Optimally, as a graduate student it would be beneficial to have multiple teaching evaluations over the years for scenarios where you are teaching varied topics or using different modes of teaching.

Teaching Certificates

A culminating opportunity available to graduate students through most CTLs is an array of teaching certificates. There are options intended to accommodate those who only have GTA experience, more advanced certificates for those who have been an instructor-of-record for a course or worked specifically to integrate technology or outreach with teaching. Investigate the teaching certificates offered by your CTL and select the option that aligns with your experiences.

Typical requirements to complete the certificates include serving for multiple semesters as a GTA or course instructor, having a CTL staff member complete a classroom observation for your teaching, attendance of teaching workshops and/or reading circles, collection of student feedback, as well as reflective writing on your teaching (personal introspection and synthesis of CTL staff/student feedback). Completing a teaching certificate is a helpful step in the growth of an engineering educator. Huang, Yellin, \& Turns (2005) concluded that Ph.D. students participating in an Engineering Teaching Portfolio Program at the University of Washington benefited greatly from the reflective thinking that accompanied the development of a teaching portfolio (similar to assembly of a teaching certificate submittal). The experiences gained from extracurricular activities and resources in the process of constructing a teaching portfolio helped students shape their teaching philosophy. 


\section{College of Engineering: Task Force for Excellence in Engineering Education}

Many research institutions have a task force within the College of Engineering that is dedicated to engineering pedagogy, which occupies a more specific domain compared to the campus center for teaching and learning. These units are often called the academy or center for excellence in engineering education (A/CE3); their primary objectives are to train newer faculty and support teaching innovation in engineering lecture/lab courses. There are student consultant opportunities one can apply for and participate, these roles exist within the A/CE3 structure largely due to the documented effectiveness of students in providing faculty feedback (as previously referenced in Redmond \& Clark 1982; Herreid \& Kozak 1995).

Observations of New Faculty

In conjunction with workshops and practicums that the A/CE3 unit hosts for newer tenure-track faculty, there is typically also a classroom observation at least once in the first year. This involves one A/CE3 representative and a student consultant who has been trained to conduct observations. The newer faculty member, A/CE3 staff, and student consultant meet for a one hour pre-observation meeting to hear from the faculty on the topic they plan to teach and the educational methods they plan to employ. For the observation, the class period is video-recorded while both $\mathrm{A} / \mathrm{CE} 3$ and student observer make written commentaries on content delivery including board/presentation notes and faculty-student interaction. The A/CE3 staff and student observer collaborate to create a brief document summarizing major successes and weaknesses of the class; these are presented to and discussed with the faculty in a one hour post-observation meeting. As a graduate student this whole cycle is an immersive learning experience where you take part in classroom observation training, critically examine several lectures from newer faculty members, hear from an expert providing feedback to the faculty, and you are also granted the opportunity to contribute your student perspective in this process.

Focus Groups to Collect Student Feedback

Another function that the A/CE3 can provide to faculty in the College of Engineering is conducting focus groups; these can be associated with or independent of human studies research that a faculty member is conducting. As an example, a chemical engineering professor may be experimenting with a flipped classroom approach where students are responsible for watching a 15-30 minute condensed video-lecture prior to attending each class and during scheduled class sessions they use that knowledge to work in teams to solve problems with instructor guidance. At the end of the semester, the professor can request an A/CE3 staff to meet with a group of students in the course and ask targeted questions to collect qualitative data on the success or possible improvements for the teaching approach. The student consultant is often recruited to assist with these focus group meetings by taking written notes of the dialogue that occurs between the staff member and the students. This is an informative experience since it can expose you to new innovations in teaching from the perspective of the student audience. 
Connections to Faculty Involved in Engineering Education Research

A benefit of serving as an A/CE3 student consultant is the exposure to an extended network of newer faculty and active engineering education researchers. These individuals may become your strongest research advisors, collaborators, or mentors as you continue in engineering education.

American Society for Engineering Education (ASEE) Collegiate Chapter

The ASEE collegiate chapter can host a range of activities that can help you develop your skillset and network as an engineering educator. Some possibilities may include: a weekly or bi-weekly reading circle where student members select journal papers to discuss; engineering education presentations by graduate students who are practicing and seeking feedback in advance of regional/national conferences or their doctoral defense; and other social events to bring together graduate students from different departments who are all passionate about education.

There are other ways to engage with ASEE on a greater scale which can include volunteering to serve as a peer reviewer for abstracts/conference papers for the national conference. Also, if you plan to attend regional or national conference, put your name forth to (co-)moderate sessions in ASEE divisions that relate to your interests. Both of these opportunities allow you to learn more about the ASEE organization, its membership, and the most current trends in research/practice related to engineering education.

Related to this topic, if you are involved as a primary or co-author on engineering education research submit your work to regional or national ASEE conferences (more on this in the following section Conducting Engineering Education Research). This enables you to disseminate your findings, and build a broader network of other students and faculty who are invested in engineering education. A word on networking via ASEE (and other engineering organizations), it is not unusual for a faculty member from another institution to hear about your work via a conference presentation and for them to approach you to either apply for an on-going faculty search or to keep an eye open for an upcoming search.

\section{Conducting Engineering Education Research}

\section{Seeking out Engineering Education Faculty Mentors}

At a research-intensive institution, aside from the programs that have departments dedicated to engineering education, it is relatively rare to find tenured faculty who have both technical engineering and education expertise. In fact, experience has shown that many engineering faculty do not realize that to formally publish student surveys or interviews on teaching activities it is necessary to complete human studies research training and submit an Institutional Review Board (IRB) application for the study. Besides the logistics to gain IRB approval for human studies research, there is an art to developing data collection instruments and coupling these with appropriate analysis techniques. That is to say that the research methodology in engineering education research is uniquely different from technical engineering research. Therefore, seek out individuals who are subject experts in the engineering education arena who can mentor you, provide you with literature that will educate you on the field, and contacts that you can speak with for further information. 
Some approaches to seek out these experts is communicating with the university center for teaching and learning, the task force within the College of Engineering dedicated to excellence in engineering education, faculty in your department who have been more vocal about pedagogy and associated research, and members of the ASEE collegiate chapter.

\section{Involvement with Engineering Education Research}

There are a few approaches to get involved with engineering education research if it is not the primary focus of your doctoral work.

Express an interest to learn and collaborate with an engineering education faculty mentor(s) that you have sought out, who may be faculty outside of your department. Investigate if they have ongoing research projects that you could assist with on a voluntary (unpaid) basis, but that would ultimately allow you to co-author papers and/or participate in poster or presentations at oncampus symposia, regional or national conferences. A slight detractor may be that the topics your mentor is investigating is slightly divergent from your area of technical expertise, though relevant to engineering education.

For a project that ties directly into your technical expertise, and is self-motivated from your experiences as a graduate teaching assistant or primary course instructor, there is another option. Work with your engineering education mentor and a technical expert to develop a research study related to efforts from "Address Concept Challenges via Curriculum Development" discussed in the previous section Capitalizing on the Teaching Assistant Role. This research project would involve devising an innovative educational approach/tool to implement in a class with which you have previously assisted, and developing data collection tools to solicit student feedback. To carry out your research you may have to seek out funding from the department or college-level to support any teaching methods that include physical models or technology tools. However, know that both the department and college maintain accounts for the purpose for improving classroom instruction; it is surprising how in some departments these monies go untouched. Additionally, you may need to recruit volunteer undergraduate or M.S. level students to assist with data collection via surveys or interviews. One effective approach is to recruit past students you have taught who believe in your promise and passion as an educator, and that are excited about how your new method would improve education. This work also can be published/presented at conferences; also consider dissemination through trade magazines and journals depending on the rigor of the research work.

In the most ideal of cases, it would be rewarding to incorporate some portion of this work in your formal dissertation. If it is directly related to your technical expertise, this is something worth discussing with your research advisor and doctoral committee. There are several researchintensive institutions that have recently started to recognize the value of teaching practicums and associated studies; there is slowly increasing trend that one chapter of the doctoral dissertation is dedicated to this type of work.

\section{Investigating Other Teaching Opportunities}

Connect with your college, department, and organizational outreach programs for opportunities to serve as a volunteer educator to young students and/or K12 educators. This could range from off-campus visits to conduct demonstrations or design activities in public school classrooms, 
providing tours to student groups on-campus in your laboratory, leading topic-specific engineering modules for on-campus summer camps, or supporting local/state-wide workshops that teach educators how to incorporate engineering in their K12 instruction. Research-intensive institutions, especially those funded as a land-grant, have a strong commitment to the community and often have College of Engineering outreach programs that serve these populations.

There may be fellowships available from specific academic groups, departments, colleges or at the university-level that supports graduate students as a primary course instructor for lectures/labs. In some instances this can be for a large cohort via a university-wide future faculty fellow programs or it can be that a department has two allocated fellowships per year. This is another reason to read the multitude of emails that come through your inbox from the college and department; sometimes it comes down to the fact that those who investigate get the opportunities.

\section{Conclusion}

The objective of this paper was to provide a cross-section of opportunities that are available at research-intensive institutions for doctoral students to develop a strong teaching portfolio that will be competitive in an application in either a primarily teaching or research institution. There are certainly other items that one can do that were not discussed, or discussed only briefly in this paper. The suggestions included in this discussion should be considered a menu of possibilities, not as a checklist where each must be completed.

A final recommendation is that that you start as early as possible with fleshing out your teaching portfolio, ideally $2+$ years prior to graduation. With this said, there are also plenty of individuals that use an additional year or two of post-doctoral work at their doctoral institution (or elsewhere) to build a successful teaching portfolio while publishing and conducting research. These decisions are a matter of how you view your timeline and personal trajectory.

There are many challenges that you will see in the path to a doctoral degree and in securing an academic position, yet know that it is possible to develop a teaching portfolio that is as robust as that of your technical engineering expertise. Hopefully, now you feel equipped with the knowledge of where you can start your studies and training in engineering education.

\section{References}

Bok, D. (2013). We Must Prepare Ph.D. Students for the Complicated Art of Teaching. The Chronicle of Higher Education.

Brent, R., \& Felder R.M. (2000). Helping New Faculty Get Off to a Good Start. Proceedings of the 2000 Annual ASEE Meeting, ASEE, St. Louis.

Felder, R.M., \& Brent R. (1996). If You've Got It, Flaunt It: Uses and Abuses of Teaching Portfolios. Chemical Engineering Education, 30(3), 188-189.

Herreid, C.F., \& Kozak, A. I. (1995). Using Students as Critics in Faculty Development. Journal on Excellence in College Teaching, 6(1), 17-29.

Huang, Y-M, Yellin, J.M.H, \& Turns, J. (2005). Future Engineering Faculty: How Do They Think about Teaching? $35^{\text {th }}$ ASEE/IEEE Frontiers in Education Conference Proceedings. 
Gaff, J.G. (2002). The Disconnect Between Graduate Education and Faculty Realities: A Review of Recent Research. Liberal Education, 88(3), 6-13.

Redmond, M.V., \& Clark, D.J. (1982). Student Group Instructional Diagnosis: A Practical Approach to Improving Teaching. AAHE Bulletin, 32(6), 8-10.

Reis, R. (1997). Tomorrow's Professor: Preparing for Academic Careers in Science and Engineering. Wiley-IEEE Press.

Seldin, P. (1993). Successful Use of Teaching Portfolios. Bolton, MA, Anker Publishing Company, Inc. 